OPEN ACCESS

Edited by:

Julie Lasselin,

Karolinska Institutet (KI), Sweden

Reviewed by:

Sven Benson,

Essen University Hospital, Germany

Mats Lekander,

Karolinska Institutet (KI), Sweden

*Correspondence: Henrik Børsting Jacobsen henrbors@uio.no

Specialty section: This article was submitted to Health Psychology, a section of the journal

Frontiers in Psychology

Received: 17 November 2020 Accepted: 01 March 2021

Published: 23 March 2021

Citation:

Munk A, Reme SE and Jacobsen HB (2021) What Does CATS Have to Do With Cancer? The Cognitive Activation Theory of Stress

(CATS) Forms the SURGE Model of Chronic Post-surgical Pain in Women With Breast Cancer.

Front. Psychol. 12:630422. doi: 10.3389/fpsyg.2021.630422

\section{What Does CATS Have to Do With Cancer? The Cognitive Activation Theory of Stress (CATS) Forms the SURGE Model of Chronic Post- surgical Pain in Women With Breast Cancer}

\author{
Alice Munk ${ }^{1}$, Silje Endresen Reme ${ }^{1,2}$ and Henrik Børsting Jacobsen ${ }^{1,2 *}$ \\ ${ }^{1}$ The Mind-Body Lab, Department of Psychology, Faculty of Social Sciences, University of Oslo, Oslo, Norway, ${ }^{2}$ Department \\ of Pain Management and Research, Oslo University Hospital, Oslo, Norway
}

Chronic post-surgical pain (CPSP) represents a highly prevalent and significant clinical problem. Both major and minor surgeries entail risks of developing CPSP, and cancer-related surgery is no exception. As an example, more than $40 \%$ of women undergoing breast cancer surgery struggle with CPSP years after surgery. While we do not fully understand the pathophysiology of CPSP, we know it is multifaceted with biological, social, and psychological factors contributing. The aim of this review is to advocate for the role of response outcome expectancies in the development of CPSP following breast cancer surgery. We propose the Cognitive Activation Theory of Stress (CATS) as an applicable theoretical framework detailing the potential role of cortisol regulation, inflammation, and inflammatory-induced sickness behavior in CPSP. Drawing on learning theory and activation theory, CATS offers psychobiological explanations for the relationship between stress and health, where acquired expectancies are crucial in determining the stress response and health outcomes. Based on existing knowledge about risk factors for CPSP, and in line with the CATS position, we propose the SURGEry outcome expectancy (SURGE) model of CPSP. According to SURGE, expectancies impact stress physiology, inflammation, and fear-based learning influencing the development and persistence of CPSP. SURGE further proposes that generalized response outcome expectancies drive adaptive or maladaptive stress responses in the time around surgery, where coping dampens the stress response, while helplessness and hopelessness sustains it. A sustained stress response may contribute to central sensitization, alterations in functional brain networks and excessive fear-based learning. This sets the stage for a prolonged state of inflammatory-induced sickness behavior - potentially driving and maintaining CPSP. Finally, as psychological factors are modifiable, robust and potent predictors of CPSP, we suggest hypnosis as an effective intervention strategy targeting response outcome expectancies. We here argue that presurgical clinical hypnosis has the potential of preventing CPSP in women with breast cancer.

Keywords: breast cancer, chronic postsurgical pain, cognitive activation theory of stress, expectancies, sickness behavior, stress, predictive coding, hypnosis 


\section{INTRODUCTION}

Chronic post-surgical pain (CPSP) affects a substantial amount of patients undergoing either major or minor surgeries (Shug and Pogatzki-Zahn, 2011). CPSP can be defined as pain that develops after surgical intervention and persists minimum 3-6 months after healed tissue damage (Cohen and Raja, 2020).

An example of debilitating CPSP is documented in women undergoing breast cancer surgery. More than 1 million women are diagnosed with breast cancer every year, and approximately $25-60 \%$ of them will struggle with CPSP, regardless of surgical procedure (Andersen and Kehlet, 2011; Wang et al., 2018b). The prevalence of severe CPSP following breast cancer surgery is estimated to be $5-10 \%$, where CPSP causes patients to experience a significant reduction in daily functioning, work capability, and quality of life (Andersen and Kehlet, 2011).

As with any chronic pain condition, the pathophysiology of CPSP in breast cancer is multifactorial, and knowledge of the underlying mechanisms is still unclear. As an example of this complexity, only some of the women with CPSP following breast cancer surgery have peripheral pain drivers as a result of intra-surgical nerve damage (Gärtner et al., 2009; Schou Bredal et al., 2014). It is therefore acknowledged that CPSP is best understood through a bio-psycho-social model, with multivariate factors contributing to its development (Weinrib et al., 2017).

Some of the more established risk factors of CPSP includes pre-surgical stress-level, depression, anxiety, pain catastrophizing, and low optimism (Jackson et al., 2016; Weinrib et al., 2017; Jensen and Johannesen, 2019; la Cour, 2019; Giusti et al., 2021). Also, pre-surgical- or intense acute post-surgical pain can significantly increase the risk of CPSP in women with breast cancer (Gärtner et al., 2009; Schou Bredal et al., 2014).

When evaluating modifiable and well-documented risk factors for CPSP following breast cancer surgery, we argue for the potential impact of expectancies on psychoneuroimmunological responses to a stressful situation. Conceptualized by an expectancy model (SURGE), we propose that CPSP can be understood, delineated, and possibly prevented. Our suggested model incorporates the cognitive activation theory of stress (CATS), predictive coding principles, cortisol function, and inflammatoryinduced sickness behavior.

\section{SETTING THE SCENE FOR CPSP: LIFE LEADING UP TO A SURGERY}

Throughout our lives, our learning history shapes expectancies, higher order beliefs about how we will respond to stressful challenges such as an impending surgery. Surgery in the context of cancer represents a highly stressful experience for most, if not all. It gives rise to multitude of expectancies of how the surgery and disease will unfold and how one is going to deal with the consequences. Dealing with such a challenge evokes past learning in the form of acquired expectancies and prior conditioning, here seen as complementary and overlapping constructs (Stewart-Williams and Podd, 2004).
Expectancies are commonly defined as "beliefs that something will happen or is likely to happen" (Schwarz et al., 2016) and can be acquired by direct experience, verbal instruction, or observation of others (Kube et al., 2017; Laferton et al., 2017; Rief and Joormann, 2019). In other words, any direct or indirect experience with surgery will contribute to the formation of expectancies. The subsequent expectancies can be colored by hope, trust, and optimism, but also by fear, worry, and catastrophic thoughts. As an example, if a loved one previously has undergone surgery and experienced CPSP, we might fear an approaching surgery.

This fear quickly becomes important as expectancies can be the powerful modulators of health outcomes (Benedetti, 2008; Kirsch, 2018; Lasselin et al., 2018). Some of the strongest effects from expectancies are seen in the placebo/nocebo literature. Positive expectancies about a given treatment can lead to increased pain relief, even if the given treatment is perceived as inactive, e.g., a calcium tablet or sham acupuncture (Benedetti, 2008; Atlas and Wager, 2012; Forsberg et al., 2017). Also, it is wellestablished that positive expectancies about the response of a given treatment may enhance the analgesic effects of active surgical (Gandhi et al., 2009), pharmacological (Bingel et al., 2011), and non-pharmacological treatments (Peerdeman et al., 2016). These processes are coined placebo analgesia. A related phenomenon is nocebo hyperalgesia. Here, negative response outcome expectancies are found to increase the intensity of pain in experimental and clinical studies (Colloca and Miller, 2011; Petersen et al., 2014). Negative expectancies about a treatment can block the analgesic effects of active treatments or exaggerate negative side effects (Petersen et al., 2014; Smith et al., 2020). While most of this research primarily focuses on experimental and acute pain, other lines of research have shown how negative expectancies can have debilitating effects on the development and maintenance of chronic pain (Atlas and Wager, 2012).

\section{COGNITIVE ACTIVATION THEORY OF STRESS}

From the moment an individual receives word about an upcoming surgery, particularly, a potential life-threatening cancer requiring surgery, a stress response usually follows. This response can be understood using the cognitive activation theory of stress (CATS), a psychobiological theoretical framework offering clear and formal definitions of the stress response and how this affects health (Ursin and Eriksen, 2004).

In CATS, "stress" is defined and operationalized as a psychobiological concept with four stages (Figure 1). The first stage is the orientation. Here, we orient toward what could be a stress stimulus, representing objective internal or external stimuli automatically processed by the brain, ultimately leading to appraisal.

The second stage is the appraisal or subjective anticipation of stress, where the stimuli have been filtered by the brain in terms of individual learning history. In CATS, learning history includes stimuli expectancies driven by classical conditioning, and response outcome expectancies driven by operant conditioning. 


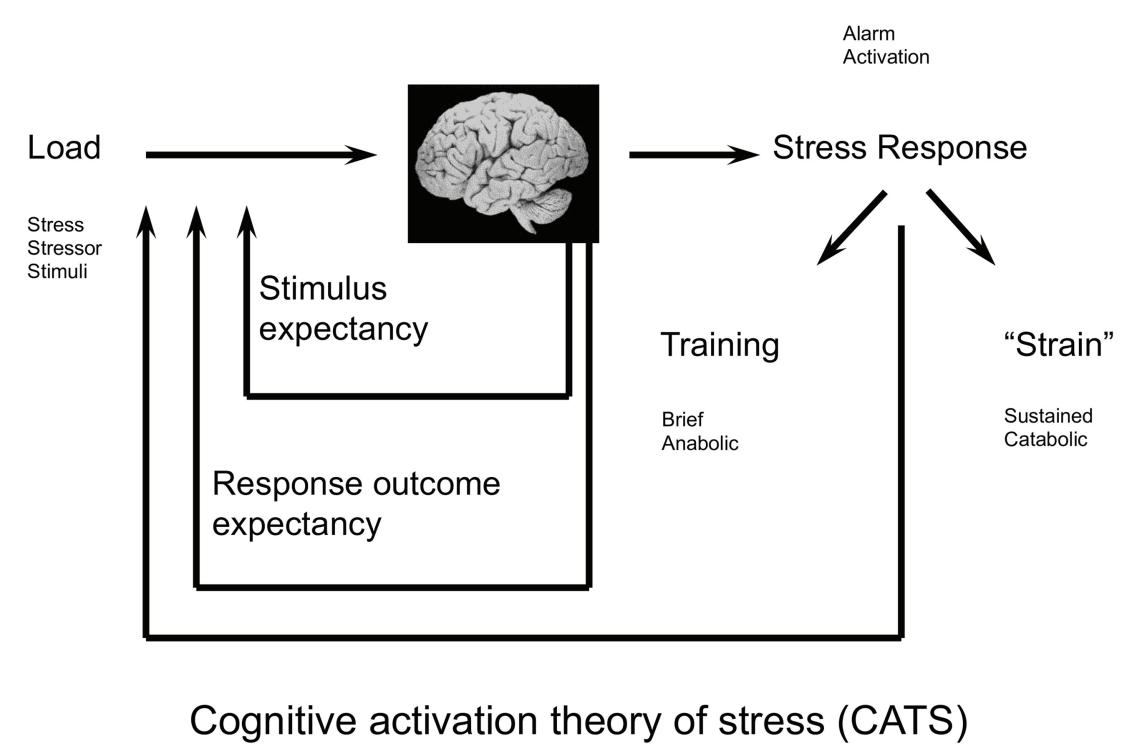

FIGURE 1 | The cognitive activation theory of stress (CATS; Ursin and Eriksen, 2010). The stress stimulus (load) is registered. Stimulus- and response- outcome expectancies influence whether the load is appraised as stressful. If so, a general physiological stress response is activated. Feedback from the physiological stress response is being fed back to the brain. A short activation of the stress response is healthy and adaptive, while a sustained stress response may lead to illness or disease. Reprinted from Ursin and Eriksen (2010), Copyright (2021) with permission from Elsevier.

These expectancies determine to a large degree intensity and duration of the third stage, the physiological stress response.

The physiological stress response is an alarm system representing a general, non-specific arousal response in the somatic and autonomic nervous system as well as in several endocrine axes (Ursin and Eriksen, 2010). The alarm goes off when an imbalance is expected in the homeostatic system, e.g., when experiencing novel or threatening stimuli or a discrepancy between what is expected and what actually is (Subjective set Value - Actual Value $\neq 0$; Ursin and Eriksen, 2010).

The fourth and final stage of the definition represents the individual experience of the stress response, consisting of information from the arousal response being fed back to the brain, ultimately maintaining, adding to, or resolving the unpleasant feeling of stress.

According to CATS, stress is a beneficial reaction, meaning that an activation of a stress response in challenging situations is healthy and adaptive. The goal of a short activation of the physiological stress response is to restore homeostasis (Ursin and Eriksen, 2004), and the arousal response is gradually turned off when the individual expects to handle the challenge successfully. If not, the arousal may be sustained, leading to illness and disease. Whether the stress response is eliminated, dampened, or sustained relies on expectancy filters (Ursin and Eriksen, 2004). These filters are described as stimulus expectancies and response outcome expectancies.

\section{Stimulus Expectancies}

Our brain is designed to store information about the relationships between sets of stimuli and our available responses
(Ursin and Eriksen, 2004). This information is stored as expectancies and is how we come to expect that one specific stimulus typically precedes another specific stimulus. In CATS, this is called as stimulus expectancies, and it represents classical conditioning within traditional learning theory (Ursin and Eriksen, 2004). A classic example of associative learning and stimulus expectancies is the work of Ivan Pavlov and his dogs. His now famous experiment showed how dogs that were continuously presented with food paired with a sound of the bell later would salivate when they heard the bell ring, regardless of food were offered or not (Pavlov and Thompson, 1902). A particular feature of Pavlovian conditioning is that stimuli sharing characteristics with the original conditioning stimuli may become capable of eliciting conditioned responses, depending on the perceptual or functional proximity between the two. This was exemplified in his studies showing that the dogs eventually started to salivate just as they heard the footsteps of the experimenters. Thus, during stimulus generalization, individuals extrapolate knowledge from one aspect of the situation to other aspects and situations - making more and more stimuli capable to elicit the conditioned response.

\section{Response Outcome Expectancies}

Response outcome expectancies are within CATS regarded as acquired information about available responses to a stimulus and how these responses affect subsequent outcomes. This type of learning follows principles of operant or instrumental conditioning, where the individual learns from positive and negative reinforcements of behavior (Ursin and Eriksen, 2004, 2010). 
Through response outcome expectancies, you anticipate successful or unsuccessful handling of future threats without yet having experienced them, an essential prerequisite for avoiding or anticipating harm.

A physiological stress response experienced by a woman who is about to undergo surgery could thus be interpreted in different ways according to her expectancies; it could either be interpreted as a sign of anxiety implicating uncontrollable danger and harm, or as a normal response to a challenging situation. While the first interpretation has the potential to increase and sustain the stress activation, the second interpretation has the potential to dampen the stress response.

The power of beliefs and expectancy in regulating physiology is a hallmark of another important learning theory, the predictive coding framework of information processing. This theory suggests that the brain uses Bayesian prediction principles to constantly match bottom-up sensory information with top-down predictions created by prior experiences (Gilbert and Sigman, 2007; Petrovic et al., 2010; Büchel et al., 2014). These predictions are organized hierarchically in the brain, from lower-level momentary hypotheses about the causes of current sensory inputs (e.g., feeling pain from a gentle touch) to increasingly more overarching beliefs the nature of the world and yourself (e.g., "I cannot cope with this pain anymore"). These higher order beliefs are in many ways analog to the concepts of stimulus expectancies and response outcome expectancy in CATS.

One can envision generalized response outcome expectancies forming enduring overarching hypotheses (e.g., "I am not a person that handles pain"). When a person experiences a discrepancy between experience and expectancy, these higher order beliefs can overturn lower-level sensory input, motivating behavior and cognition in order to uphold an expectancy, regardless of lower level input and prediction errors. This has been described as cognitive immunization and is particularly evident in patients with depression (Kube et al., 2020). Numerous studies show how patients suffering from depression are prone to maintain their negative expectancies despite of positive, contradictory evidence (Korn et al., 2014; Liknaitzky et al., 2017; Everaert et al., 2018). This immunization contrasts that of a healthy population who show an overall optimism bias, i.e., a tendency mainly to update expectancies if new information are positive, while maintaining one's prior belief if the presented evidence is negative (Sharot, 2011).

The notion of a hierarchical organization of processing is also described in CATS through the feedback loop in the model, where lower level peripheral changes - i.e., the stress response - is being fed back to the brain, but can be prolonged or dampened according to higher order expectancies or predictions (Ursin and Eriksen, 2004). Principles from the predictive coding framework thus align with the expectancy principles outlined in CATS. In effect, generalized expectancies based on prior experiences can then override lower-level changes and new learning, potentially maintaining a stress response in the weeks leading up to breast cancer surgery. The CATS model has further specified three forms of generalized response outcome expectancies, namely coping, helplessness and hopelessness.

\section{Coping}

A significant contribution from CATS is its clarification of the coping term and its assumed correlates. Coping in CATS terminology is the acquired expectancy that most or all responses to a situation will lead to a positive outcome. Thus, it represents an anticipatory cognitive construct rather than objective abilities or strategies that could be applied in challenging situations. Coping in form of generalized response outcome expectancy may be associated with a proactive appraisal of the stressful situation, reflecting improved anticipatory stress regulation, ultimately resulting in a shortened physiological stress response (Ursin and Eriksen, 2004).

In the case of a woman undergoing breast cancer surgery, coping may refer to the expectancy of being able to handle the stressful aspects of the surgery, i.e., the post-surgical pain and potential side effects in a successful way. This taps into the established CPSP resilience factors of dispositional optimism (Powell et al., 2012) and self-efficacy (Weinrib et al., 2017).

According to CATS, it is when coping is defined as a generalized response outcome expectancy it may hold the strongest predictive power for health outcomes, mediated by its presumed reducing effects on the strength and the duration of the physiological stress response (Ursin and Eriksen, 2004, 2010). The authors of CATS argue that since coping defined as coping strategies can be carried out under various levels and lengths of arousal, it is not a robust predictor of stressrelated illness or disease (Ursin and Eriksen, 2004).

Both human and animal studies suggest that positive expectancy attenuates the cortisol response to stress. Rats exposed to shocks will initially show high behavioral and endocrine arousal. However, in late stages of avoidance learning tasks when they have established that they will be able to escape the shocks, the arousal diminishes to a minimum (Coover et al., 1973). Ursin and Eriksen (2004) suggest that this happens so rapidly and efficient that it is not just a result of the avoidance behavior, but due to an expectancy that the behavior will lead to a successful outcome.

Ursin et al. (1978) also tested this position in humans. A group of novel parachutist trainees showed the high levels of endocrine and subjective reported arousal before their first jump. Already after their first training session, before there had been any real improvement of their performance, the arousal reduced significantly. This could indicate that it was not the actual performance, but the acquired expectancy of being able to handle the situation with a positive result, that explained the diminished stress response.

Recent studies of how we react to psychosocial stress confirm and expand upon these early reports of positive physiological effects from cognitive re-framing and coping. Jamieson et al. (2012) showed that during a psychosocial stress test, participants instructed to reappraise their arousal in a positive way had increased cardiac efficiency, lower vascular resistance, and decreased attentional bias. Similarly, Nasso et al. (2019) showed that when anticipating a stressful 
task (i.e., giving a speech), individuals using an adaptive cognitive emotion regulation strategy showed better anticipatory stress regulation than individuals prone to worry or catastrophizing. Overall, these results suggest that positive response outcome expectancies can affect the long-term consequences of our physiological stress responses in a beneficial fashion.

\section{Helplessness and Hopelessness}

Helplessness refers to the acquired expectancy of one's actions having no impact on the outcome of an aversive event. This can be exemplified by a woman going into breast cancer surgery with the expectancy that there is nothing she can do to control the outcome of the surgery or potential negative side effects. A qualitative study by Lie et al. (2018) highlighted how young adult cancer patients, aged 18-35 years at time of diagnosis, describe that not being able to predict or control their situation was the most stressful aspect of all stages of their disease and treatment. This study focuses on patients in a particular vulnerable transitional life period. However, other studies find similar results on helplessness, i.e., the factors of uncertainty and lack of perceived control are common characteristics of stress and chronic disease, with negative effects on pain outcomes and quality of life (Johnson et al., 2006; Müller, 2011; Caruso et al., 2014; Engevold and Heggdal, 2016).

Hopelessness, on the other hand, is an expectancy of most or all responses leading to negative outcomes. In women with breast cancer going into surgery, this could be the expectancy that all attempts to handle or change the stressful situation evolving around the surgery, will only make it worse. Hopelessness implies that there is control, responses have effects, but they are all negative. These failed attempts combined with the assumed control could evoke feelings of guilt and self-blame in those who acquire expectancies of hopelessness. Thus, these expectancies are proposed by the authors of CATS as a cognitive model for depression (Ursin and Eriksen, 2004), a condition that increases the risk of developing CPSP (Weinrib et al., 2017).

The expectancies of helplessness and hopelessness are also conceptually close to another established risk factor of CPSP namely pain catastrophizing. When measured with the Pain Catastrophizing Scale (PCS; Sullivan et al., 1996), this is a strong and consistent predictor of CPSP (Hannibal and Bishop, 2014; Johannsen et al., 2018, 2020). In PCS, patients report about helplessness and hopelessness in response to pain (e.g., "It's terrible and I think it's never going to get any better" and "there's nothing I can do to reduce the intensity of the pain"; Sullivan et al., 1996). Moreover, the elements of hopelessness are captured within measures of injustice experiences (The Injustice Experience Questionnaire; Sullivan et al., 2008), which also is a significant psychological risk factor for developing CPSP (Yakobov et al., 2014).

In summary, CATS states that coping may reduce or eliminate the physiological stress response, and helplessness and hopelessness may sustain it. If sustained, the stress response affects specific psychological and neurobiological mechanisms that can reinforce and perpetuate pain relating to the surgery, increasing the risk for developing CPSP.

\section{Stress and Sensitization}

A line of experimental studies have demonstrated the link between a sustained stress response and the process of sensitization, which is suggested as a psychobiological mechanism in the transition from acute to chronic pain (Ursin, 2014). On the cellular level, sensitization is defined as an increased efficiency in a neural circuit, due to a change in synapses from repeated use (Collingridge et al., 2004). Sensitization of pain pathways in the central nervous system is widely accepted as a theory of neural mechanisms enhancing pain transmission (Ikeda et al., 2009). This central sensitization progressively amplifies the responses to pain stimuli. It manifests as pain hypersensitivity both as a reduction in pain threshold and an increase in pain responsiveness as well prolonged after sensations and an expansion of the receptive field (Woolf, 2011).

A large body of evidence showing central sensitization in chronic pain syndromes originates from research on patients with fibromyalgia, a condition with widespread pain in the body. Research has demonstrated widespread reductions in pain thresholds as well as an increased temporal summation and a spatial area of pain in this patient group (Gibson et al., 1994; Lorenz et al., 1996; Graven-Nielsen et al., 2000). Patients with CPSP also show the signs of central sensitization (Woolf, 2011; Johannsen et al., 2020). The role of central sensitization in CPSP is further supported by an indication of pain reducing effects due to centrally acting agents such as ketamine (Remérand et al., 2009), pregabalin (Mathiesen et al., 2009; Burke and Shorten, 2010), gabapentin (Sen et al., 2009; Verret et al., 2020), and duloxetine (Ho et al., 2010). However, more studies are needed to establish the effectiveness of pharmacological treatments.

Pre-surgical pain in the surgical area as well as other sites of the body is the strong predictors of CPSP (Poleshuck et al., 2006; Kudel et al., 2007; Gärtner et al., 2009; Nikolajsen and Aasvang, 2019). Patients who experience pre-surgical pain conditions, such as fibromyalgia, migraine, or chronic low back pain, have a significant increased risk of CPSP following breast cancer surgery (Bruce et al., 2012; Schou Bredal et al., 2014). The association between pre- and post-surgical pain could be due to an unknown common underlying factor (e.g., genetic and/or psychological), making a group of patients more vulnerable to persistent pain. Still, it could suggest that a central sensitization plays a role in CPSP through repeated pain stimuli increasing the efficiency and excitability of central pain pathways or stated another way; pain produces pain.

Different lines of research thus present the hypothesis that sensitized stress responses could interact with sensitized pain responses, and ultimately increase the risk of CPSP. However, it has proven difficult to establish direct causal delineation of sustained stress in chronic pain, but psychological and physiological stress is associated frequently with the development and persistence of chronic disease such as chronic pain conditions (McEwen and Kalia, 2010; Timmers et al., 2019). In a CATS perspective, sustained activation is the motor that accelerates 
sensitization and prevents its reversibility, thus sustained stress activation will affect almost all bodily systems through the actions of cortisol. As principles of central sensitization likely contribute to the chronification of pain (Woolf, 2011), the potential maladaptive effects of stress hormones on pain transmission could mediate the relationship between chronic stress and chronic pain.

\section{Cortisol Function and Chronic Pain}

Cortisol is a catabolic hormone produced in the adrenal cortex, which plays a crucial part in the physiological stress response (Hannibal and Bishop, 2014). In stressful situations, cortisol levels rise to provide energy to deal with the situation or escape danger (fight or flight; Blackburn-Munro and BlackburnMunro, 2003). Prolonged cortisol secretion, on the other hand, could have damaging effects and increase the risk of chronic pain.

During the stress response, unbound cortisol binds on glucocorticoid receptors (GRs) resulting in anti-inflammatory and pain inhibiting mechanisms (Fries et al., 2005; Sorrells et al., 2009). However, an exaggerated or sustained cortisol secretion may cause GR to downregulate, or block cortisol binding, ultimately creating cortisol dysfunction (Norman and Hearing, 2002). Further, an impaired binding to GR might disrupt the negative feedback loop, which under normal circumstances enables cortisol to regulate the release of corticotrophin-releasing hormone (CRH) (Fries et al., 2005). CRH upregulates glutamate and N-methyl-D-aspartate (NMDA) in the amygdala, which might set prime for a conditioned fear-based stress response (Tsigos and Chrousos, 2002; Shekhar et al., 2005; McEwen and Kalia, 2010). Additionally, it is indicated that the activation of $\mathrm{CRH}$ receptors in the amygdala may trigger pain in the absence of tissue damage and that hyperpolarized postsynaptic potentials might be able to make amygdala resistant to inhibitory signals from prefrontal cortex (Shekhar et al., 2005; Ji et al., 2013). Such reduced prefrontal modulation is associated with pain catastrophizing in chronic pain patients experiencing intense pain (Seminowicz and Davis, 2006).

Several studies have associated the actions of cortisol with increased activation in the amygdala during anxiety and fear (Shekhar et al., 2005; Ji et al., 2013; Vachon-Presseau et al., 2013). Using an animal model of neuropathic pain in rats, $\mathrm{Li}$ et al. (2013) found that lesions of the basolateral amygdala inhibit the transition from acute to chronic pain in the early stages of nerve damage. Due to the well-established role of the amygdala in the fear learning system, the authors suggest that a possible explanation of this involves interruptions of negative emotions and consolidation of fear-based pain memories. Such learning processes may possibly relate to the acquisition of negative response outcome expectancies, potentially leading to sustained activation, sensitization and chronic pain.

Pain catastrophizing, i.e., a sense of helplessness and hopelessness, elevates the cortisol secretion and sustains the activation of the stress response (Johansson et al., 2008; Quartana et al., 2010; Müller, 2011). Sustained activation of a sensitized stress response exhausts the HPA-axis, and chronic stressinduced hypocortisolism has been linked to chronic pain conditions (Tsigos and Chrousos, 2002; Tak and Rosmalen, 2010; Hannibal and Bishop, 2014). Paradoxically, hypercortisolism is also reported as a contributor to chronic pain (BlackburnMunro and Blackburn-Munro, 2003; Dedovic et al., 2009), i.e., potentially mediated by the blunted feedback mechanisms discussed earlier in this section. The relationship between stress, chronic pain, and hypo- and hyper-cortisolism thus depend on temporal aspects of measurement, the individualized stress response, the different mechanisms of cortisol dysfunction described earlier and numerous situation-specific factors (Hannibal and Bishop, 2014). These inconsistencies call for more research on the relationship between cortisol and chronic pain, but available data suggest that stress-induced cortisol dysfunction could contribute to the development and persistence of chronic pain.

Cortisol dysfunction through the mechanisms discussed above represents potential harmful effects of sustained activation on a neurochemical level. In addition, prolonged secretion of stress hormones may alter both the functional and physical properties of the corticolimbic system with considerable consequences for the development and perpetuation of chronic pain following breast cancer surgery.

\section{Corticolimbic Plasticity}

The corticolimbic circuit of the brain consists of neural loops between structures such as the prefrontal cortex (PFC), the amygdala, the hippocampus, and hypothalamus in strong connections to the HPA-axis (Vachon-Presseau, 2018). The corticolimbic circuit is involved in a variation of cognitiveemotional processes and plays a crucial role in motivation and learning, i.e., in relation to pain and the anticipation of pain (Ploghaus et al., 2001; Apkarian et al., 2009). It has been suggested that the corticolimbic circuit may represent the primary system through which nociception accesses consciousness and is experienced as pain (Baliki and Apkarian, 2015). The corticolimbic structures show high affinity to stress hormones, which enable them to regulate the stress response through feedback loops to the HPA axis, and at the same time making them sensitive to the effects of long-term exposure to cortisol (Radley and Sawchenko, 2011; Vachon-Presseau, 2018).

The PFC is particular sensitive to the effects of stress hormones. Sustained exposure to cortisol has shown to generate extensive dendritic spine loss (Arnsten, 2009; McEwen and Morrison, 2013) similar to that observed in medial prefrontal cortex (mPFC) in animal models of neuropathic pain (Metz et al., 2009). Moreover, the mPFC has been associated with individual differences in subjective pain intensity in chronic pain patients. For example, an fMRI study by Baliki et al. (2012) indicated that the strength of the functional connectivity between mPFC and nucleus accumbens (NAc) is a dominating predictor of pain chronification in humans with subacute back pain (stronger mPFC-NAc connectivity was associated with pain persistence). The activity of the PFC regulates, and is regulated by, the amygdala. In animal models of chronic pain, the excitability of neurons in the amygdala rapidly increases in response to repeated pain stimuli (Ursin, 2014). This increased excitability compliments animal models showing hypertrophy 
and increased spinogenesis in basolateral regions of the amygdala when animals are exposed to sustained stress (Roozendaal et al., 2009). Studies of post-traumatic stress disorder in humans expand upon this indicating that both pain and fear-based learning can drive hypertrophy in these regions of the amygdala (Morey et al., 2020). The increased activity and hypertrophy of the amygdala divergently affects plasticity in other brain regions such as the PFC and hippocampus (Patel et al., 2018). The amygdala then influences the corticolimbic circuit by modulating excitability of the inhibitory neurons in the mPFC, as well as neurons in the spinal cord (Neugebauer et al., 2004; Neugebauer, 2015), which may result in pain hypersensitivity. Thus, the connectivity between the amygdala and the PFC may be distorted by long-term exposure to cortisol, mediated by CRH as well as GR signaling (Galatzer-Levy et al., 2017), which have implications for the regulation of anxiety and pain (Shekhar et al., 2005; Ji et al., 2013).

Finally, several studies have implicated that alterations in the physical and functional features of the hippocampus are associated with chronic pain conditions. Using an animal model of neuropathic pain, Mutso et al. (2012) found decreased hippocampal neurogenesis and altered hippocampal shortterm synaptic plasticity in mice with spared nerve-injury neuropathic pain compared with sham animals. In addition, this study found lower hippocampal volume in patients suffering from low back pain and complex regional pain syndrome. The authors propose that the functional hippocampal abnormalities found in their animal model of neuropathic pain potentially relate to the decreased hippocampal volume observed in chronic pain conditions, and that this ultimately contributes to emotional and learning deficits associated with chronic pain. The deteriorating effects of stress hormones on hippocampal volume and neurogenesis are indicated in both aging (Lupien et al., 1998) and psychiatric populations (Sapolsky, 2000; Videbech and Ravnkilde, 2004).

In summary, the corticolimbic system may be sensitive to maladaptive effects of long-term exposure to stress hormones, both in terms of its physical and functional properties. These stress-induced changes in the corticolimbic circuit may negatively affect the regulation of the stress response by impairing the inhibitory feedback loops from the HPA axis (Vachon-Presseau, 2018). This could contribute to a vicious cycle sustaining the activation of the stress response and presents direct and indirect implications for the chronification and experience of pain in a woman entering surgery for breast cancer.

\section{PERI- AND POSTOPERATIVE STRESS - THE CRUCIAL TIME JUST BEFORE, DURING, AND AFTER SURGERY}

In the perioperative phase, breast cancer patients often experience high levels of distress and expect a variety of post-surgery symptoms (Deane and Degner, 1998; Spencer et al., 1999). Such distress may include everything from concerns about diagnosis and prognosis (Schnur et al., 2008), to concerns about anesthesia (Shevde and Panagopoulos, 1991), and surgical procedures (e.g., pain during procedure and postoperative side effects; Klafta and Roizen, 1996). Pre-surgery distress and patient expectancies about the severity of postoperative side effects have both been found to predict pain severity, nausea, and fatigue 1 week after surgery in breast cancer patients (Montgomery et al., 2010). In addition, patients' presurgical expectancies of pain, fatigue, and nausea have been shown to partially mediate the effects of distress on pain severity 1 week after surgery, where expectancies and psychological distress together explained $28 \%$ of the variance in 1 week post-surgery pain (Montgomery et al., 2010). In CATS terminology, this would entail background arousal (high distress), stimulus expectancies (severe pain from surgery), and response outcome expectancies ("I have no power over what's to come"), resulting in a tonic (sustained) arousal with increased risk of negative health consequences (e.g., pain and other side effects 1 week after surgery).

A breast cancer surgery usually involves either total removal of the breast (mastectomy) or breast-conserving surgery (lumpectomy) with or without sentinel node biopsy. Breast conserving surgery is a less invasive yet a safe and effective option (Fisher et al., 1989) and is the most commonly performed surgery (Lazovich et al., 1999). While breast conserving surgery has fewer early post-operative complications (Chatterjee et al., 2015) and has been associated with better quality of life (Sun et al., 2014), incidence rates of CPSP appear to be less influenced by type of surgery (Wang et al., 2016). Instead, CPSP is heavily influenced by emotional distress, which has led to a general call for ways to target the emotional distress, since this is a modifiable risk factor that could be intervened on (Jackson et al., 2016). In a recent study, those women with the highest level of distress after surgery were those who benefited the most from a psychological treatment (Wang et al., 2018a,b). We therefore argue that from a prevention perspective, timing of the intervention is crucial. The time window immediately before surgery, on the day of surgery, is critical. If distress is reduced and coping increased already prior to surgery, an important risk factor for CPSP and other negative health outcomes could be eliminated, ultimately affecting the prognosis and risk for CPSP.

\section{Inflammation, Sickness Behavior, and Post-surgical Pain}

Stress, inflammation, and pain are inherently interlinked systems, whether you look at it from an acute or chronic perspective. Both pro- and anti-inflammatory processes kick in, in response to stressors such as pain, perceived or anticipated danger, injury, and infection (Slavich and Cole, 2013). A short-term pro-inflammatory response increases the chance of survival by accelerating wound healing and limit potential spread of an infection. In addition, pro-inflammatory cytokine activity, involving tumor necrosis factor- $\alpha$ (TNF- $\alpha$ ) and interleukins $1 \beta$ and 6 (IL- $1 \beta$ and IL-6), promote a distinct motivational state called as sickness behavior, observed in both human and animals (Hart, 1988; Dantzer, 2001; Shattuck and Muehlenbein, 2016).

The cluster of behavioral symptoms that constitutes sickness behavior includes fatigue, pain hypersensitivity, psychomotor retardation, social withdrawal, and decreased interest in hedonic 
behaviors (Dantzer, 2001; Lasselin et al., 2020). Sickness behavior also involves an emotional component, i.e., heightened emotional distress, which are evident in humans exposed to experimentally induced inflammation (Lasselin et al., 2018). This motivational state lowers (social) activities in order to facilitate recovery and decrease the risk of spreading an infection to conspecifics. In addition, hypervigilance involving pain hypersensitivity and emotional distress would motivate the vulnerable organism to tend to one's wounds and stay away from potential danger while recovering.

As with the stress response, a short increased inflammation and subsequent sickness behavior is adaptive and desirable. However, the inflammation and sickness behavior need to subside for health and healing to take place. Unfortunately, fear-based learning, threat monitoring (i.e., searching for pain in the area of surgery), and sustained stress can maintain inflammation processes through stress-driven alterations in the nucleuses of the amygdala. Recent imaging studies in humans have shown how a hyperactive amygdala activates leukopoietic tissue in the bone marrow, increasing arterial inflammation (Tawakol et al., 2019) and C-reactive protein (CRP) (Osborne et al., 2020). Elevated levels of CRP are strongly associated with reduced pain tolerance and increased pain sensitivity (Schistad et al., 2017), and increased pain sensitivity would increase acute post-operative pain, furthering the risk of developing CPSP (Wilder-Smith, 2011).

Increased inflammation in persistent pain also has a behavioral analog. Using a cross-sectional design, Jonsjö et al. (2020) concluded that chronic pain patients report high levels of sickness behavior (assessed with a validated questionnaire for subjective sickness behavior, Sickness Q; Andreasson et al., 2018). The level of sickness behavior in chronic pain patients was similar to the levels reported by healthy volunteers following injection with a lipopolysaccharide (LPS), a method used to induce a strong inflammatory response in human or animals (Jonsjö et al., 2020; Lasselin et al., 2020). LPS-injected individuals report higher pain sensitivity compared to controls, and the increase in pain sensitivity correlates with lower activation in the ventrolateral prefrontal cortex and the rostral anterior cingulate cortex - areas associated with top-down pain modulation (Karshikoff et al., 2016). Moreover, when compared to others, the levels of self-reported sickness behavior in chronic pain patients and LPS-injected individuals are significantly higher than general care patients and healthy subjects (Jonsjö et al., 2020).

In sum, when undergoing breast cancer surgery, the surgery naturally and adaptively elicits stress-, immune-, and painresponses. Inflammatory-induced sickness behavior serves adaptive and protective functions in the acute post-surgical phase. However, if the women undergoing surgery enter and exit the surgery with brain alterations and increased inflammation driven by a sustained stress response, this could result in pain hypersensitivity and hypervigilance toward pain following in the weeks after surgery. This fits with persistent sickness behavior mirroring these alterations. While neural and humoral pathways that restore homeostasis may terminate sickness behavior, the same sickness behavior processes can be maintained without an ongoing infection (Jonsjö et al., 2020), possibly through inflammation driven by a sustained stress response.

Significantly elevated levels of the pro-inflammatory cytokine interleukin 6 (IL-6) are found in chronic pain patients compared to healthy controls (Koch et al., 2007). In addition, increased plasma concentrations of TNF- $\alpha$ and IL- $1 \beta$, other common markers of low-grade systemic inflammation, were detected in chronic pain patients with severe pain, though not in patients with light or moderate pain, suggesting a potential role of low-grade inflammation in chronic pain at least when pain intensity exceeds a certain threshold (Koch et al., 2007). Overall, higher plasma concentrations of inflammatory markers correlate with higher self-reported pain intensity (Koch et al., 2007). As cytokines are thought to be the main mediators in this stress-induced pro-inflammatory effect, this has led to low grade pro-inflammatory processes being proposed as a biological mechanism directly contributing to the pathophysiology of stress-related diseases (Rohleder, 2014).

The previous sections have discussed various mechanisms through which sustained stress activation may contribute to CPSP following breast cancer surgery. Sickness behavior, cortisol dysfunction, and alterations in the corticolimbic circuit due to prolonged secretion of cortisol are essential. They combine to drive the physical and functional irregularities characteristic for chronic pain states, as evident in human and animal studies. Moreover, disrupted corticolimbic connectivity has negative consequences for the regulation of the HPA-axis through its inhibitory feedback loops. The potential maladaptive effects of long-term exposure to stress hormones are important aspects of the vicious cycle of chronic stress and chronic pain, preventing the "alarm" to be turned off, and enabling the stress and pain to persist many years after surgery.

Common to the proposed pathophysiological mechanisms of a stress-induced transition from acute to chronic pain is the involvement of various forms of learning. The corticolimbic circuit, in particular, the amygdala and the hippocampus, is essential in learning and consolidation of fear-based memories, i.e., in response to pain (Hannibal and Bishop, 2014; VachonPresseau, 2018). This contributes to the conditioning of a sensitized stress response, readily activated in response to pain (Hannibal and Bishop, 2014). It seems reasonable to hypothesize, that the corticolimbic pathways play a role in the conditioning of response outcome expectancies. Helplessness and hopelessness in response to pain relate to outcomes with strong affective value during high arousal, which make it likely to involve activation of limbic pathways. Furthermore, the relationship is likely bidirectional, in such that hopelessness and helplessness sustain the stress response and contribute to the long-term exposure and maladaptive effects of stress hormones on the corticolimbic circuit.

\section{THE SURGE MODEL}

According to SURGE, generalized response outcome expectancies in form of helplessness and hopelessness sustain a physiological stress response before and after surgery. This sets the stage 
for fear-based learning, pain sensitization, and maladaptive effects from stress hormones. Moreover, the sustained stress response may contribute to increased pro-inflammatory activity in the peri- and post-operative phase. An increased and prolonged inflammatory state may lead to chronic sickness behavior with its characteristic cluster of hyperalgesia, emotional distress, and other debilitating behaviors.

We here propose that the SURGE model of CPSP (Figure 2) offers a possible explanation on how acute pain following breast cancer surgery may develop into CPSP depending on generalized response outcome expectancies. The model further proposes which psychobiological mechanisms drive this transition in form of a sustained activation of the stress response and inflammatory processes. Moreover, the model suggests targets for interventions that could prevent the development of CPSP in women with breast cancer.

\section{HOW TO ADDRESS THE PROBLEM: MANAGING EXPECTANCIES}

If response outcome expectancies are an important driver in the development of CPSP, mediated by sustained stress activation, a change in these expectancies should be followed by reduced stress activation and a correspondingly reduced risk of acute as well as CPSP. Challenging and changing negative expectations are fundamental to several psychological interventions. In cognitive behavioral therapy (CBT), unhelpful cognitions are targeted and challenged with a goal of reversing thoughts of helplessness and hopelessness (Beck and Dozois, 2011). The efficacy of CBT has been demonstrated in several populations and settings, including women with breast cancer (Antoni, 2013), with evidence from self-reported outcomes as well as cancerrelevant biological outcomes (McGregor and Antoni, 2009). A more recent approach from the third generation CBT is Acceptance and Commitment Therapy, which also holds promise as a valuable adjunct to surgical interventions (Weinrib et al., 2017).

Nevertheless, in the myriad of psychological interventions and techniques, one particular intervention stands out as notably potent in the context of surgery namely clinical hypnosis. Verbal suggestions appear to be a particularly powerful way of changing expectancies, and this very element is refined and perfected in hypnosis. The seminal study by Montgomery et al. (2007) demonstrates the effects of a hypnosis in women undergoing breast cancer surgery, where a brief session of hypnosis focusing on increasing coping expectancies right before surgery, produced large reductions in pain, distress, and discomfort immediately after surgery.

Hypnosis has been defined in various ways, but is most often described as a state of highly focused attention and increased suggestibility (Lynn et al., 2010). It is often compared to the everyday state of becoming so immersed in a good book

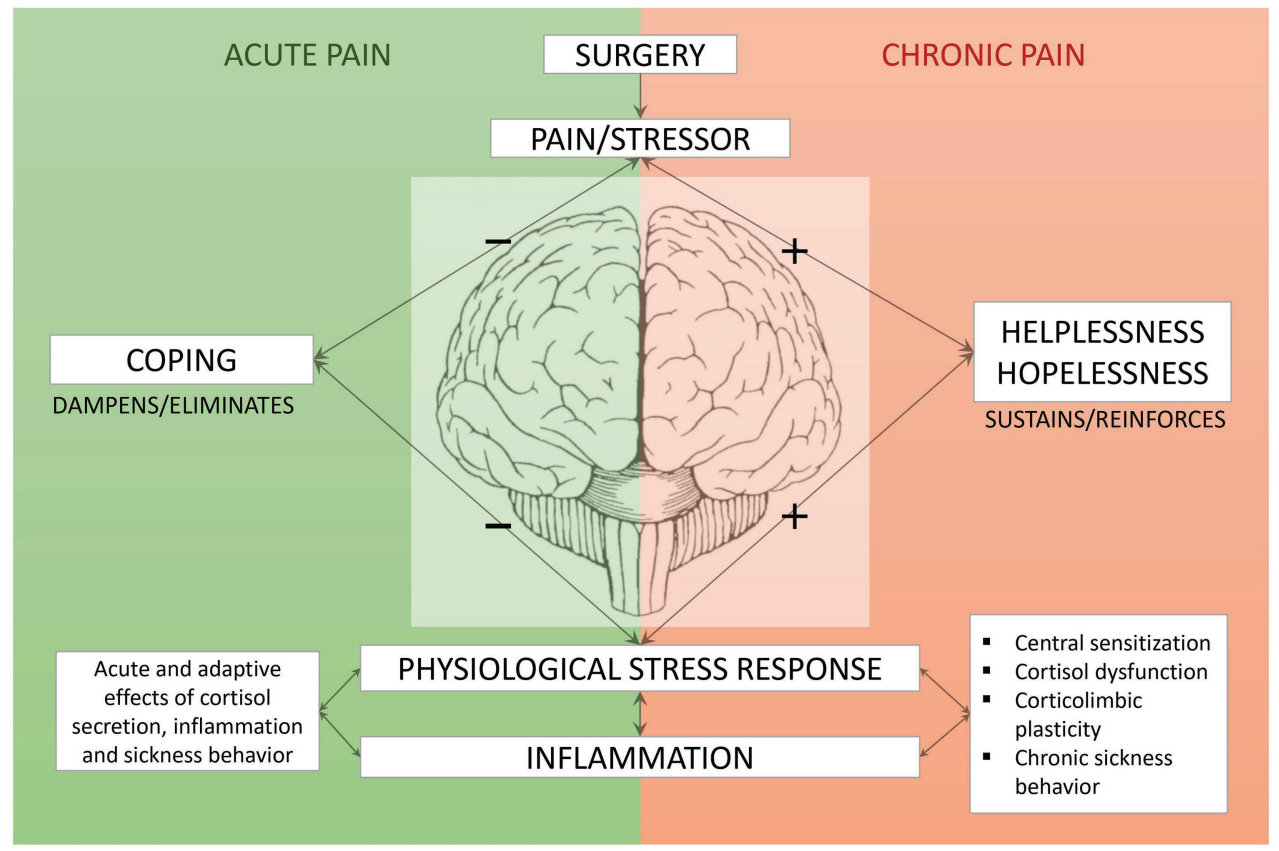

FIGURE 2 | The SURGE Model of chronic post-surgical pain in women with breast cancer: surgery activates the central nervous system and creates acute pain. In line with CATS- and predictive-coding framework principles, the pain is appraised based on previous experiences in form of response outcome expectancies. An expectancy of being able to handle the pain with a positive outcome (coping) dampens or eliminates the physiological stress response. An expectancy of not being able to control or influence the pain (helplessness) or only making the pain worse (hopelessness) sustain the activation of the stress response. The sustained activation creates a vicious cycle of chronic stress, chronic inflammation, and chronic pain mediated by pathophysiological mechanisms such as central sensitization, cortisol dysfunction, impairment of corticolimbic connectivity, and inflammatory-induced sickness behavior. 
or a movie that you enter the imagined world and loose contact with the real world (Lang et al., 2000; Montgomery et al., 2002).

The evidence-base for clinical hypnosis as an effective adjunctive non-pharmacological analgesia is strong, as demonstrated in several articles and meta-analyses in top-tier journals (Lang et al., 2000; Montgomery et al., 2002; Tefikow et al., 2013; Kekecs et al., 2014). Of particular relevance here are effects that involve pain reduction, reduced need for medication, and shorter duration of surgery, with effect sizes indicating better clinical outcomes in patients receiving hypnosis than $89 \%$ of patients in control groups (Montgomery et al., 2002). Hypnosis has further been shown to be superior to other psychological techniques (e.g., therapeutic suggestions; Kekecs et al., 2014) and might also provide benefits when delivered during general anesthesia (Berlière et al., 2018; Lacroix et al., 2019; Nowak et al., 2020). While studies of long-term effects of hypnosis are scarce, one recent study indicates the potential for preventing CPSP with peri-operative hypnosis (Berlière et al., 2018) in line with the SURGE model of CPSP.

\section{Mechanisms of Hypnotic Analgesia}

Exactly how hypnotic analgesia works is heavily debated and not agreed upon. While some insists that hypnosis involves an altered state of consciousness (Lynn et al., 2010) others refer to hypnosis as a cognitive behavioral technique (Montgomery et al., 2007), implying that it works through the same system as placebo analgesia works through. Our approach is mostly in line with the latter position. Consistent with the SURGE model, we propose that hypnotic analgesia might work through hypnotic suggestions inducing positive coping expectancies in response to surgery and pain, leading to a dampening of the physiological stress response and ultimately a decrease in pain intensity and a lower risk of developing CPSP.

Nevertheless, earlier studies have demonstrated that hypnotic analgesia could occur through other systems than through the endogenous pain inhibitory mechanisms within the central nervous system that placebo works through (Barber and Mayer, 1977). Injections of naloxone, which is an opioid antagonist, have for instance not been able to change the elevated pain threshold induced by hypnosis in acute (Barber and Mayer, 1977) or in chronic pain (Spiegel and Albert, 1983).

Rather than a placebo effect "in disguise," or an altered state of consciousness, we argue that hypnotic analgesia instead involves an altered perception. This has been suggested by leading experts in the field (Spiegel, 2007) and aligns well with the SURGE model. Through a mobilization of attention pathways in the brain brought about by hypnosis, specific instructions are given that alters the experience of pain and associated anxiety.

\section{REFERENCES}

Andersen, K. G., and Kehlet, H. (2011). Persistent pain after breast cancer treatment: a critical review of risk factors and strategies for prevention. J. Pain 12, 725-746. doi: 10.1016/j.jpain.2010.12.005

Andreasson, A., Wicksell, R. K., Lodin, K., Karshikoff, B., Axelsson, J., and Lekander, M. (2018). A global measure of sickness behavior: development
The recent predictive coding approaches have also shown relevance to hypnosis. By suggesting that hypnosis causes a shift in the default mode network (DMN; Carhart-Harris and Friston, 2019), an opportunity is created for the psychotherapeutic context surrounding the administration to establish longer-term changes in predictive coding activity. By increasing their sensitivity toward prediction errors, otherwise stable beliefs become more easily updated (Carhart-Harris and Friston, 2019). Furthermore, bottom-up information that is normally inhibited by compressive beliefs becomes liberated and is allowed to "travel up the (brainbody) hierarchy with greater latitude and compass" (Carhart-Harris and Friston, 2019). A central characteristic of this state is increased context sensitivity, i.e., a heightened susceptibility toward ongoing processes in the internal and external context. The hypnosis session then becomes a catalyst creating a unique opportunity to modulate behavioral activation in order to promote a functional homeostasis (Greenway et al., 2020). We propose that all the mentioned findings on mechanisms involved in hypnotic analgesia are in fact not contradictory, but instead pointing toward a common ground - the role of stress and expectancies.

\section{CONCLUSION}

Acute pain after breast cancer surgery is expected and adaptive, while the development from acute to CPSP represents a highly prevalent and significant clinical problem. Overall, CPSP is a multifaceted syndrome involving physiological, cognitive, and emotional factors (in addition to important socioeconomic aspects, which have not been discussed here). Expectancy effects are well-established in pain research, showing how expectancies strongly modulate acute and experimental pain. By applying CATS and principles from predictive coding framework, this review has argued how expectancies might contribute to chronic pain, in the specific case of CPSP following breast cancer surgery - mediated by sustained activation, inflammatory-induced sickness behavior, sensitization, and the neurotoxic effects of stress hormones. Clinical hypnosis is suggested as an effective intervention strategy targeting response outcome expectancies, with the potential of preventing CPSP in women with breast cancer.

\section{AUTHOR CONTRIBUTIONS}

HJ conceived the idea to the manuscript. AM and SR provided critical intellectual input to the disposition and conceptual framework. AM performed the literature review and wrote the first draft of the manuscript. All authors contributed to the conceptualization, writing, and approval of the final manuscript. of the sickness questionnaire. J. Health Psychol. 23, 1452-1463. doi: $10.1177 / 1359105316659917$

Antoni, M. H. (2013). Psychosocial intervention effects on adaptation, disease course and biobehavioral processes in cancer. Brain Behav. Immun. 30 (Suppl), S88-S98. doi: 10.1016/j.bbi.2012.05.009

Apkarian, A. V., Baliki, M. N., and Geha, P. Y. (2009). Towards a theory of chronic pain. Prog. Neurobiol. 87, 81-97. doi: 10.1016/j.pneurobio.2008.09.018 
Arnsten, A. F. T. (2009). Stress signalling pathways that impair prefrontal cortex structure and function. Nat. Rev. Neurosci. 10, 410-422. doi: 10.1038/nrn2648

Atlas, L. Y., and Wager, T. D. (2012). How expectations shape pain. Neurosci. Lett. 520, 140-148. doi: 10.1016/j.neulet.2012.03.039

Baliki, M. N., and Apkarian, A. V. (2015). Nociception, pain, negative moods, and behavior selection. Neuron 87, 474-491. doi: 10.1016/j.neuron.2015.06.005

Baliki, M. N., Petre, B., Torbey, S., Herrmann, K. M., Huang, L., Schnitzer, T. J., et al. (2012). Corticostriatal functional connectivity predicts transition to chronic back pain. Nat. Neurosci. 15, 1117-1119. doi: 10.1038/nn.3153

Barber, J., and Mayer, D. (1977). Evaluation of the efficacy and neural mechanism of a hypnotic analgesia procedure in experimental and clinical dental pain. Pain 4, 41-48. doi: 10.1016/0304-3959(77)90085-9

Beck, A. T., and Dozois, D. J. A. (2011). Cognitive therapy: current status and future directions. Annu. Rev. Med. 62, 397-409. doi: 10.1146/annurevmed-052209-100032

Benedetti, F. (2008). Mechanisms of placebo and placebo-related effects across diseases and treatments. Annu. Rev. Pharmacol. Toxicol. 48, 33-60. doi: 10.1146/annurev.pharmtox.48.113006.094711

Berlière, M., Roelants, F., Watremez, C., Docquier, M. A., Piette, N., Lamerant, S., et al. (2018). The advantages of hypnosis intervention on breast cancer surgery and adjuvant therapy. Breast 37, 114-118. doi: 10.1016/j. breast.2017.10.017

Bingel, U., Wanigasekera, V., Wiech, K., Ni Mhuircheartaigh, R., Lee, M. C., Ploner, M., et al. (2011). The effect of treatment expectation on drug efficacy: imaging the analgesic benefit of the opioid remifentanil. Sci. Transl. Med. 3:70ra14. doi: 10.1126/scitranslmed.3001244

Blackburn-Munro, G., and Blackburn-Munro, R. (2003). Pain in the brain: are hormones to blame? Trends Endocrinol Metab 14, 20-27. doi: 10.1016/ S1043-2760(02)00004-8

Bruce, J., Thornton, A. J., Scott, N. W., Marfizo, S., Powell, R., Johnston, M., et al. (2012). Chronic preoperative pain and psychological robustness predict acute postoperative pain outcomes after surgery for breast cancer. $\mathrm{Br}$. J. Cancer 107, 937-946. doi: 10.1038/bjc.2012.341

Büchel, C., Geuter, S., Sprenger, C., and Eippert, F. (2014). Placebo analgesia: a predictive coding perspective. Neuron 81, 1223-1239. doi: 10.1016/j. neuron.2014.02.042

Burke, S. M., and Shorten, G. D. (2010). Perioperative pregabalin improves pain and functional outcomes 3 months after lumbar discectomy. Anesth. Analg. 110, 1180-1185. doi: 10.1213/ANE.0b013e3181cf949a

Carhart-Harris, R. L., and Friston, K. J. (2019). REBUS and the anarchic brain: TOWARD a unified model of the brain action of psychedelics. Pharmacol. Rev. 71, 316-344. doi: 10.1124/pr.118.017160

Caruso, V., Giammanco, M. D., and Gitto, L. (2014). Quality of life and uncertainty in illness for chronic patients. Mediterr. J. Clin. Psychol. 2, 1-12. doi: 10.6092/2282-1619/2014.2.990

Chatterjee, A., Pyfer, B., Czerniecki, B., Rosenkranz, K., Tchou, J., and Fisher, C. (2015). Early postoperative outcomes in lumpectomy versus simple mastectomy. J. Surg. Res. 198, 143-148. doi: 10.1016/j.jss.2015.01.054

Cohen, S. P., and Raja, S. N. (2020). "Pain" in Goldman-cecil medicine. 26 Edn. eds. L. Goldman and A. I. Schafer (Elsevier Inc.), 128-137.

Collingridge, G. L., Isaac, J. T. R., and Wang, Y. T. (2004). Receptor trafficking and synaptic plasticity. Nat. Rev. Neurosci. 5, 952-962. doi: 10.1038/nrn1556

Colloca, L., and Miller, F. G. (2011). The nocebo effect and its relevance for clinical practice. Psychosom. Med. 73, 598-603. doi: 10.1097/PSY.0b013e 3182294a50

Coover, G. D., Ursin, H., and Levine, S. (1973). Plasma-corticosterone levels during active-avoidance learning in rats. J. Comp. Physiol. Psychol. 82, 170-174. doi: 10.1037/h0033790

Dantzer, R. (2001). Cytokine-induced sickness behavior: where do we stand? Brain Behav. Immun. 15, 7-24. doi: 10.1006/brbi.2000.0613

Deane, K. A., and Degner, L. F. (1998). Information needs, uncertainty, and anxiety in women who had a breast biopsy with benign outcome. Cancer Nurs. 21, 117-126. doi: 10.1097/00002820-199804000-00005

Dedovic, K., Duchesne, A., Andrews, J., Engert, V., and Pruessner, J. C. (2009). The brain and the stress axis: the neural correlates of cortisol regulation in response to stress. NeuroImage 47, 864-871. doi: 10.1016/j.neuroimage. 2009.05.074

Engevold, M. H., and Heggdal, K. (2016). Patients' experiences with changes in perceived control in chronic illness: a pilot study of the outcomes of a new health promotion program in community health care. Scandinavian Psychologist. 3:e5. doi: 10.15714/scandpsychol.3.e5

Everaert, J., Bronstein, M. V., Cannon, T. D., and Joormann, J. (2018). Looking through tinted glasses: depression and social anxiety are related to both interpretation biases and inflexible negative interpretations. Clin. Psychol. Sci. 6, 517-528. doi: 10.1177/2167702617747968

Fisher, B., Redmond, C., Poisson, R., Margolese, R., Wolmark, N., Wickerham, L., et al. (1989). Eight-year results of a randomized clinical trial comparing total mastectomy and lumpectomy with or without irradiation in the treatment of breast cancer. N. Engl. J. Med. 320, 822-828. doi: 10.1056/NEJM19890 3303201302

Forsberg, J. T., Martinussen, M., and Flaten, M. A. (2017). The placebo analgesic effect in healthy individuals and patients: a meta-analysis. Psychosom. Med. 79, 388-394. doi: 10.1097/PSY.0000000000000432

Fries, E., Hesse, J., Hellhammer, J., and Hellhammer, D. H. (2005). A new view on hypocortisolism. Psychoneuroendocrinology 30, 1010-1016. doi: 10.1016/j.psyneuen.2005.04.006

Galatzer-Levy, I. R., Andero, R., Sawamura, T., Jovanovic, T., Papini, S., Ressler, K. J., et al. (2017). A cross species study of heterogeneity in fear extinction learning in relation to FKBP5 variation and expression: implications for the acute treatment of posttraumatic stress disorder. Neuropharmacology 116, 188-195. doi: 10.1016/j.neuropharm.2016.12.023

Gandhi, R., Davey, J. R., and Mahomed, N. (2009). Patient expectations predict greater pain relief with joint arthroplasty. J. Arthroplast. 24, 716-721. doi: 10.1016/j.arth.2008.05.016

Gärtner, R., Jensen, M. B., Nielsen, J., Ewertz, M., Kroman, N., and Kehlet, H. (2009). Prevalence of and factors associated with persistent pain following breast cancer surgery. JAMA 302, 1985-1992. doi: 10.1001/jama.2009.1568

Gibson, S. J., Littlejohn, G. O., Gorman, M. M., Helme, R. D., and Granges, G. (1994). Altered heat pain thresholds and cerebral event-related potentials following painful CO2 laser stimulation in subjects with fibromyalgia syndrome. Pain 58, 185-193. doi: 10.1016/0304-3959(94)90198-8

Gilbert, C. D., and Sigman, M. (2007). Brain states: top-down influences in sensory processing. Neuron 54, 677-696. doi: 10.1016/j.neuron.2007.05.019

Giusti, E. M., Lacerenza, M., Manzoni, G. M., and Castelnuovo, G. (2021). Psychological and psychosocial predictors of chronic postsurgical pain: a systematic review and meta-analysis. Pain 162, 10-30. doi: 10.1097/j. pain.0000000000001999

Graven-Nielsen, T., Aspegren Kendall, S., Henriksson, K. G., Bengtsson, M., Sörensen, J., Johnson, A., et al. (2000). Ketamine reduces muscle pain, temporal summation, and referred pain in fibromyalgia patients. Pain 85, 483-491. doi: 10.1016/S0304-3959(99)00308-5

Greenway, K. T., Garel, N., Jerome, L., and Feduccia, A. A. (2020). Integrating psychotherapy and psychopharmacology: psychedelic-assisted psychotherapy and other combined treatments. Expert. Rev. Clin. Pharmacol. 13, 655-670. doi: 10.1080/17512433.2020.1772054

Hannibal, K. E., and Bishop, M. D. (2014). Chronic stress, cortisol dysfunction, and pain: a psychoneuroendocrine rationale for stress management in pain rehabilitation. Phys. Ther. 94, 1816-1825. doi: 10.2522/ptj.20130597

Hart, B. L. (1988). The behavior of sick animals. Vet. Clin. North Am. Small Anim. Pract. 21, 225-237. doi: 10.1016/S0195-5616(91)50028-0

Ho, K. -Y., Tay, W., Yeo, M. -C., Liu, H., Yeo, S. -J., Chia, S. -L., et al. (2010). Duloxetine reduces morphine requirements after knee replacement surgery. Br. J. Anaesth. 105, 371-376. doi: 10.1093/bja/aeq158

Ikeda, H., Kiritoshi, T., and Murase, K. (2009). Synaptic plasticity in the spinal dorsal horn. Neurosci. Res. 64, 133-136. doi: 10.1016/j.neures.2009.03.004

Jackson, T., Tian, P., Wang, Y., Iezzi, T., and Xie, W. (2016). Toward identifying moderators of associations between presurgery emotional distress and postoperative pain outcomes: a meta-analysis of longitudinal studies. J. Pain 17, 874-888. doi: 10.1016/j.jpain.2016.04.003

Jamieson, J. P., Nock, M. K., and Mendes, W. B. (2012). Mind over matter: reappraising arousal improves cardiovascular and cognitive responses to stress. J. Exp. Psychol. Gen. 141, 417-422. doi: 10.1037/a0025719

Jensen, N. -H., and Johannesen, N. (2019). "Den kroniske smertepatient 1: Alment" in Smerter: baggrund, evidens, behandling. 4th Edn. eds. M. U. Werner, N. B. Finnerup and L. Arendt-Nielsen (København: FADL), 444-457.

Ji, G., Fu, Y., Adwanikar, H., and Neugebauer, V. (2013). Non-pain-related CRF1 activation in the amygdala facilitates synaptic transmission and pain responses. Mol. Pain 9:2. doi: 10.1186/1744-8069-9-2 
Johannsen, M., Frederiksen, Y., Jensen, A. B., and Zachariae, R. (2018). Psychosocial predictors of posttreatment pain after nonmetastatic breast cancer treatment: a systematic review and meta-analysis of prospective studies. J. Pain Res. 11, 23-36. doi: 10.2147/JPR.S124665

Johannsen, M., Jensen, A. B., Jespersen, T. W., and Zachariae, B. (2020). "Vedvarende smerter efter kræftbehandling" in Livet efter kræeft. 1st Edn. eds. B. Zachariae and M. Y. Mehlsen (Roskilde: FADL), 36-52.

Johansson, A. -C., Gunnarsson, L. -G., Linton, S. J., Bergkvist, L., Stridsberg, M., Nilsson, O., et al. (2008). Pain, disability and coping reflected in the diurnal cortisol variability in patients scheduled for lumbar disc surgery. Eur. J. Pain 12, 633-640. doi: 10.1016/j.ejpain.2007.10.009

Johnson, L. M., Zautra, A. J., and Davis, M. C. (2006). The role of illness uncertainty on coping with fibromyalgia symptoms. Health Psychol. 25, 696-703. doi: 10.1037/0278-6133.25.6.696

Jonsjö, M. A., Åström, J., Jones, M. P., Karshikoff, B., Lodin, K., Holmström, L., et al. (2020). Patients with ME/CFS (Myalgic Encephalomyelitis/Chronic Fatigue Syndrome) and chronic pain report similar level of sickness behavior as individuals injected with bacterial endotoxin at peak inflammation. Brain Behav. Immun. Health 2:100028. doi: 10.1016/j.bbih.2019.100028

Karshikoff, B., Jensen, K. B., Kosek, E., Kalpouzos, G., Soop, A., Ingvar, M., et al. (2016). Why sickness hurts: a central mechanism for pain induced by peripheral inflammation. Brain Behav. Immun. 57, 38-46. doi: 10.1016/j. bbi.2016.04.001

Kekecs, Z., Nagy, T., and Varga, K. (2014). The effectiveness of suggestive techniques in reducing postoperative side effects: a meta-analysis of randomized controlled trials. Anesth. Analg. 119, 1407-1419. doi: 10.1213/ANE.0000 000000000466

Kirsch, I. (2018). Response expectancy and the placebo effect. Int. Rev. Neurobiol. 138, 81-93. doi: 10.1016/bs.irn.2018.01.003

Klafta, J. M., and Roizen, M. F. (1996). Current understanding of patients' attitudes toward and preparation for anesthesia: a review. Anesth. Analg. 83, 1314-1321. doi: 10.1097/00000539-199612000-00031

Koch, A., Zacharowski, K., Boehm, O., Stevens, M., Lipfert, P., von Giesen, H. J., et al. (2007). Nitric oxide and pro-inflammatory cytokines correlate with pain intensity in chronic pain patients. Inflamm. Res. 56, 32-37. doi: 10.1007/ s00011-007-6088-4

Korn, C. W., Sharot, T., Walter, H., Heekeren, H. R., and Dolan, R. J. (2014). Depression is related to an absence of optimistically biased belief updating about future life events. Psychol. Med. 44, 579-592. doi: 10.1017/S00332 91713001074

Kube, T., D’Astolfo, L., Glombiewski, J. A., Doering, B. K., and Rief, W. (2017). Focusing on situation-specific expectations in major depression as basis for behavioural experiments - Development of the Depressive Expectations Scale. Psychol. Psychother. Theory Res. Pract. 90, 336-352. doi: 10.1111/papt.12114

Kube, T., Rozenkrantz, L., Rief, W., and Barsky, A. (2020). Understanding persistent physical symptoms: conceptual integration of psychological expectation models and predictive processing accounts. Clin. Psychol. Rev. 76:101829. doi: 10.1016/j.cpr.2020.101829

Kudel, I., Edwards, R. R., Kozachik, S., Block, B. M., Agarwal, S., Heinberg, L. J., et al. (2007). Predictors and consequences of multiple persistent postmastectomy pains. J. Pain Symptom Manag. 34, 619-627. doi: 10.1016/j.jpainsym man.2007.01.013

la Cour, P. (2019). "Smertepsykologi" in Smerter: baggrund, evidens, behandling. 4th Edn. eds. M. U. Werner, N. B. Finnerup and L. Arendt-Nielsen (Roskilde: FADL), $112-130$.

Lacroix, C., Duhoux, F. P., Bettendorff, J., Watremez, C., Roelants, F., Docquier, M. -A., et al. (2019). Impact of perioperative hypnosedation on postmastectomy chronic pain: preliminary results. Integr. Cancer Ther. 18, 1534735419869494. doi: 10.1177/1534735419869494

Laferton, J. A. C., Kube, T., Salzmann, S., Auer, C. J., and Shedden-Mora, M. C. (2017). Patients' expectations regarding medical treatment: a critical review of concepts and their assessment. Front. Psychol. 8:233. doi: 10.3389/ fpsyg.2017.00233

Lang, E. V., Benotsch, E. G., Fick, L. J., Lutgendorf, S., Berbaum, M. L., Berbaum, K. S., et al. (2000). Adjunctive non-pharmacological analgesia for invasive medical procedures: a randomised trial. Lancet 355, 1486-1490. doi: $10.1016 / \mathrm{S} 0140-6736(00) 02162-0$

Lasselin, J., Petrovic, P., Olsson, M. J., Paues Göranson, S., Lekander, M., Jensen, K. B., et al. (2018). Sickness behavior is not all about the immune response: possible roles of expectations and prediction errors in the worry of being sick. Brain Behav. Immun. 74, 213-221. doi: 10.1016/j.bbi.2018.09.008

Lasselin, J., Schedlowski, M., Karshikoff, B., Engler, H., Lekander, M., and Konsman, J. P. (2020). Comparison of bacterial lipopolysaccharide-induced sickness behavior in rodents and humans: relevance for symptoms of anxiety and depression. Neurosci. Biobehav. Rev. 115, 15-24. doi: 10.1016/j.neubiorev.2020.05.001

Lazovich, D., Solomon, C. C., Thomas, D. B., Moe, R. E., and White, E. (1999). Breast conservation therapy in the United States following the 1990 National Institutes of Health consensus development conference on the treatment of patients with early stage invasive breast carcinoma. Cancer 86, 628-637. doi: 10.1002/(SICI)1097-0142(19990815)86:4<628::AID-CNCR11>3.0.CO;2-L

Li, Z., Wang, J., Chen, L., Zhang, M., and Wan, Y. (2013). Basolateral amygdala lesion inhibits the development of pain chronicity in neuropathic pain rats. PloS One 8:e70921. doi: 10.1371/journal.pone.0070921

Lie, N. E. K., Larsen, T. M. B., and Hauken, M. A. (2018). Coping with changes and uncertainty: a qualitative study of young adult cancer patients' challenges and coping strategies during treatment. Eur. J. Cancer Care 27, 1-10. doi: 10.1111/ecc.12743

Liknaitzky, P., Smillie, L. D., and Allen, N. B. (2017). Out-of-the-blue: depressive symptoms are associated with deficits in processing inferential expectancyviolations using a novel cognitive rigidity task. Cogn. Ther. Res. 41, 757-776. doi: 10.1007/s10608-017-9853-x

Lorenz, J., Grasedyck, K., and Bromm, B. (1996). Middle and long latency somatosensory evoked potentials after painful laser stimulation in patients with fibromyalgia syndrome. Electroencephalogr. Clin. Neurophysiol. 100, 165-168. doi: 10.1016/0013-4694(95)00259-6

Lupien, S. J., de Leon, M., de Santi, S., Convit, A., Tarshish, C., Nair, N. P., et al. (1998). Cortisol levels during human aging predict hippocampal atrophy and memory deficits. Nat. Neurosci. 1, 69-73. doi: 10.1038/271

Lynn, S. J., Rhue, J. W., and Kirsch, I. (2010). Handbook of clinical hypnosis. 2nd Edn. Washington, DC: American Psychological Association.

Mathiesen, O., Rasmussen, M. L., Dierking, G., Lech, K., Hilsted, K. L., Fomsgaard, J. S., et al. (2009). Pregabalin and dexamethasone in combination with paracetamol for postoperative pain control after abdominal hysterectomy. A randomized clinical trial. Acta Anaesthesiol. Scand. 53, 227-235. doi: 10.1111/j.1399-6576.2008.01821.x

McEwen, B. S., and Kalia, M. (2010). The role of corticosteroids and stress in chronic pain conditions. Metab. Clin. Exp. 59 (Suppl. 1), S9-S15. doi: 10.1016/j.metabol.2010.07.012

McEwen, B. S., and Morrison, J. H. (2013). The brain on stress: vulnerability and plasticity of the prefrontal cortex over the life course. Neuron 79, 16-29. doi: $10.1016 /$ j.neuron.2013.06.028

McGregor, B. A., and Antoni, M. H. (2009). Psychological intervention and health outcomes among women treated for breast cancer: a review of stress pathways and biological mediators. Brain Behav. Immun. 23, 159-166. doi: 10.1016/j.bbi.2008.08.002

Metz, A. E., Yau, H. -J., Centeno, M. V., Apkarian, A. V., and Martina, M. (2009). Morphological and functional reorganization of rat medial prefrontal cortex in neuropathic pain. Proc. Natl. Acad. Sci. 106, 2423-2428. doi: 10.1073/pnas.0809897106

Montgomery, G. H., Bovbjerg, D. H., Schnur, J. B., David, D., Goldfarb, A., Weltz, C. R., et al. (2007). A randomized clinical trial of a brief hypnosis intervention to control side effects in breast surgery patients. J. Natl. Cancer Inst. 99, 1304-1312. doi: 10.1093/jnci/djm106

Montgomery, G. H., David, D., Winkel, G., Silverstein, J. H., and Bovbjerg, D. H. (2002). The effectiveness of adjunctive hypnosis with surgical patients: a meta-analysis. Anesth. Analg. 94, 1639-1645. doi: 10.1097/00000539-20020600000052

Montgomery, G. H., Schnur, J. B., Erblich, J., Diefenbach, M. A., and Bovbjerg, D. H. (2010). Presurgery psychological factors predict pain, nausea, and fatigue one week after breast cancer surgery. J. Pain Symptom Manag. 39, 1043-1052. doi: 10.1016/j.jpainsymman.2009.11.318

Morey, R. A., Clarke, E. K., Haswell, C. C., Phillips, R. D., Clausen, A. N., Mufford, M. S., et al. (2020). Amygdala nuclei volume and shape in military veterans with posttraumatic stress disorder. Biol. Psychiatry Cogn. Neurosci. Neuroimaging 5, 281-290. doi: 10.1016/j.bpsc.2019.11.016

Müller, M. J. (2011). Helplessness and perceived pain intensity: relations to cortisol concentrations after electrocutaneous stimulation in healthy young men. Biopsychosoc. Med. 5:8. doi: 10.1186/1751-0759-5-8 
Mutso, A. A., Radzicki, D., Baliki, M. N., Huang, L., Banisadr, G., Centeno, M. V., et al. (2012). Abnormalities in hippocampal functioning with persistent pain. J. Neurosci. 32, 5747-5756. doi: 10.1523/JNEUROSCI.0587-12.2012

Nasso, S., Vanderhasselt, M. A., Demeyer, I., and De Raedt, R. (2019). Autonomic regulation in response to stress: the influence of anticipatory emotion regulation strategies and trait rumination. Emotion, 19, 443-454. doi: 10.1037/emo0000448

Neugebauer, V. (2015). Amygdala pain mechanisms BT-Pain control. ed. H. -G. Schaible (Berlin, Heidelberg: Springer), 261-284.

Neugebauer, V., Li, W., Bird, G. C., and Han, J. S. (2004). The amygdala and persistent pain. Neuroscientist 10, 221-234. doi: 10.1177/1073858403261077

Nikolajsen, L., and Aasvang, E. (2019). "Kroniske postoperative smerter" in Smerter: baggrund, evidens, behandling. 4th Edn. eds. M. U. Werner, N. B. Finnerup and L. Arendt-Nielsen (København: FADL), 290-301.

Norman, M., and Hearing, S. D. (2002). Glucocorticoid resistance-what is known? Curr. Opin. Pharmacol. 2, 723-729. doi: 10.1016/S1471-4892(02)00232-1

Nowak, H., Zech, N., Asmussen, S., Rahmel, T., Tryba, M., Oprea, G., et al. (2020). Effect of therapeutic suggestions during general anaesthesia on postoperative pain and opioid use: multicentre randomised controlled trial. BMJ 371:m4284. doi: 10.1136/bmj.m4284

Osborne, M. T., Abohashem, S., Zureigat, H., Abbasi, T. A., and Tawakol, A. (2020). Multimodality molecular imaging: gaining insights into the mechanisms linking chronic stress to cardiovascular disease. J. Nucl. Cardiol. doi: 10.1007/ s12350-020-02424-6 [Epub ahead of print]

Patel, D., Anilkumar, S., Chattarji, S., and Buwalda, B. (2018). Repeated social stress leads to contrasting patterns of structural plasticity in the amygdala and hippocampus. Behav. Brain Res. 347, 314-324. doi: 10.1016/j.bbr.2018.03.034

Pavlov, I. P., and Thompson, W. H. (1902). The work of the digestive glands: lectures by Professor J. P. Pawlow. London: C. Griffin.

Peerdeman, K. J., van Laarhoven, A. I. M., Keij, S. M., Vase, L., Rovers, M. M., Peters, M. L., et al. (2016). Relieving patients' pain with expectation interventions: a meta-analysis. Pain 157, 1179-1191. doi: 10.1097/j.pain.0000 000000000540

Petersen, G. L., Finnerup, N. B., Colloca, L., Amanzio, M., Price, D. D., Jensen, T. S., et al. (2014). The magnitude of nocebo effects in pain: a meta-analysis. Pain 155, 1426-1434. doi: 10.1016/j.pain.2014.04.016

Petrovic, P., Kalso, E., Petersson, K. M., Andersson, J., Fransson, P., and Ingvar, M. (2010). A prefrontal non-opioid mechanism in placebo analgesia. Pain 150, 59-65. doi: 10.1016/j.pain.2010.03.011

Ploghaus, A., Narain, C., Beckmann, C. F., Clare, S., Bantick, S., Wise, R., et al. (2001). Exacerbation of pain by anxiety is associated with activity in a hippocampal network. J. Neurosci. Off. J. Soc. Neurosci. 21, 9896-9903. doi: 10.1523/JNEUROSCI.21-24-09896.2001

Poleshuck, E. L., Katz, J., Andrus, C. H., Hogan, L. A., Jung, B. F., Kulick, D. I., et al. (2006). Risk factors for chronic pain following breast cancer surgery: a prospective study. J. Pain 7, 626-634. doi: 10.1016/j.jpain.2006.02.007

Powell, R., Johnston, M., Smith, W. C., King, P. M., Chambers, W. A., Krukowski, Z., et al. (2012). Psychological risk factors for chronic postsurgical pain after inguinal hernia repair surgery: a prospective cohort study. Eur. J. Pain 16, 600-610. doi: 10.1016/j.ejpain.2011.08.010

Quartana, P. J., Buenaver, L. F., Edwards, R. R., Klick, B., Haythornthwaite, J. A., and Smith, M. T. (2010). Pain catastrophizing and salivary cortisol responses to laboratory pain testing in temporomandibular disorder and healthy participants. J. Pain 11, 186-194. doi: 10.1016/j.jpain.2009.07.008

Radley, J. J., and Sawchenko, P. E. (2011). A Common substrate for prefrontal and hippocampal inhibition of the neuroendocrine stress response. J. Neurosci. 31, 9683-9695. doi: 10.1523/JNEUROSCI.6040-10.2011

Remérand, F., Le Tendre, C., Baud, A., Couvret, C., Pourrat, X., Favard, L., et al. (2009). The early and delayed analgesic effects of ketamine after total hip arthroplasty: a prospective, randomized, controlled, double-blind study. Anesth. Analg. 109, 1963-1971. doi: 10.1213/ANE.0b013e3181bdc8a0

Rief, W., and Joormann, J. (2019). Revisiting the cognitive model of depression: the role of expectations. Clin. Psychol. Eur. 1. doi: 10.32872/cpe.v1i1.32605

Rohleder, N. (2014). Stimulation of systemic low-grade inflammation by psychosocial stress. Psychosom. Med. 76, 181-189. doi: 10.1097/PSY.0000000000000049

Roozendaal, B., McEwen, B. S., and Chattarji, S. (2009). Stress, memory and the amygdala. Nat. Rev. Neurosci. 10, 423-433. doi: 10.1038/nrn2651

Sapolsky, R. M. (2000). Glucocorticoids and hippocampal atrophy in neuropsychiatric disorders. Arch. Gen. Psychiatry 57, 925-935. doi: 10.1001/ archpsyc.57.10.925
Schistad, E. I., Stubhaug, A., Furberg, A. S., Engdahl, B. L., and Nielsen, C. S. (2017). C-reactive protein and cold-pressor tolerance in the general population: the Tromsø study. Pain 158, 1280-1288. doi: 10.1097/j.pain.0000000000000912

Schnur, J. B., Montgomery, G. H., Hallquist, M. N., Goldfarb, A. B., Silverstein, J. H., Weltz, C. R., et al. (2008). Anticipatory psychological distress in women scheduled for diagnostic and curative breast cancer surgery. Int. J. Behav. Med. 15, 21-28. doi: 10.1007/BF03003070

Schou Bredal, I., Smeby, N. A., Ottesen, S., Warncke, T., and Schlichting, E. (2014). Chronic pain in breast cancer survivors: comparison of psychosocial, surgical, and medical characteristics between survivors with and without pain. J. Pain Symptom Manag. 48, 852-862. doi: 10.1016/j.jpainsymman. 2013.12.239

Schwarz, K. A., Pfister, R., and Büchel, C. (2016). Rethinking explicit expectations: connecting placebos, social cognition, and contextual perception. Trends Cogn. Sci. 20, 469-480. doi: 10.1016/j.tics.2016.04.001

Seminowicz, D. A., and Davis, K. D. (2006). Cortical responses to pain in healthy individuals depends on pain catastrophizing. Pain 120, 297-306. doi: 10.1016/j.pain.2005.11.008

Sen, H., Sizlan, A., Yanarates, O., Emirkadi, H., Ozkan, S., Dagli, G., et al. (2009). A comparison of gabapentin and ketamine in acute and chronic pain after hysterectomy. Anesth. Analg. 109, 1645-1650. doi: 10.1213/ ANE.0b013e3181b65ea0

Sharot, T. (2011). The optimism bias. Curr. Biol. 21, R941-R945. doi: 10.1016/j. cub.2011.10.030

Shattuck, E. C., and Muehlenbein, M. P. (2016). Towards an integrative picture of human sickness behavior. Brain Behav. Immun. 57, 255-262. doi: 10.1016/j. bbi.2016.05.002

Shekhar, A., Truitt, W., Rainnie, D., and Sajdyk, T. (2005). Role of stress, corticotrophin releasing factor (CRF) and amygdala plasticity in chronic anxiety. Stress 8, 209-219. doi: 10.1080/10253890500504557

Shevde, K., and Panagopoulos, G. (1991). A survey of 800 patients' knowledge, attitudes, and concerns regarding anesthesia. Anesth. Analg. 73, 190-198 doi: 10.1213/00000539-199108000-00013

Shug, S. A., and Pogatzki-Zahn, E. M. (2011). Chronic pain after surgery or injury. Pain Clin. Updates 19, 1-5. doi: 10.1016/j.mpsur.2016.11.005

Slavich, G. M., and Cole, S. W. (2013). The emerging field of human social genomics. Clin. Psychol. Sci. 1, 331-348. doi: 10.1177/2167702613478594

Smith, L. E., Webster, R. K., and Rubin, G. J. (2020). A systematic review of factors associated with side-effect expectations from medical interventions. Health Expect. 23, 1-28. doi: 10.1111/hex.13059

Sorrells, S. F., Caso, J. R., Munhoz, C. D., and Sapolsky, R. M. (2009). The stressed CNS: when glucocorticoids aggravate inflammation. Neuron 64, 33-39. doi: 10.1016/j.neuron.2009.09.032

Spencer, S. M., Lehman, J. M., Wynings, C., Arena, P., Carver, C. S., Antoni, M. H., et al. (1999). Concerns about breast cancer and relations to psychosocial well-being in a multiethnic sample of early-stage patients. Health Psychol. 18, 159-168. doi: 10.1037/0278-6133.18.2.159

Spiegel, D. (2007). The mind prepared: hypnosis in surgery. JNCI 99, 1280-1281. doi: $10.1093 /$ jnci/djm131

Spiegel, D., and Albert, L. H. (1983). Naloxone fails to reverse hypnotic alleviation of chronic pain. Psychopharmacology 81, 140-143. doi: 10.1007/BF00429008

Stewart-Williams, S., and Podd, J. (2004). The placebo effect: dissolving the expectancy versus conditioning debate. Psychol. Bull. 130, 324-340. doi: 10.1037/0033-2909.130.2.324

Sullivan, M. J. L., Adams, H., Horan, S., Maher, D., Boland, D., and Gross, R. (2008). The role of perceived injustice in the experience of chronic pain and disability: scale development and validation. J. Occup. Rehabil. 18, 249-261. doi: 10.1007/s10926-008-9140-5

Sullivan, M. J. L., Bishop, S., and Pivik, J. (1996). The pain catastrophizing scale: development and validation. Psychol. Assess. 7, 524-532. doi: 10.1037//1040-3590.7.4.524

Sun, Y., Kim, S. W., Heo, C. Y., Kim, D., Hwang, Y., Yom, C. K., et al. (2014). Comparison of quality of life based on surgical technique in patients with breast cancer. Jpn. J. Clin. Oncol. 44, 22-27. doi: 10.1093/jjco/hyt176

Tak, L. M., and Rosmalen, J. G. M. (2010). Dysfunction of stress responsive systems as a risk factor for functional somatic syndromes. J. Psychosom. Res. 68, 461-468. doi: 10.1016/j.jpsychores.2009.12.004

Tawakol, A., Osborne, M. T., Wang, Y., Hammed, B., Tung, B., Patrich, T., et al. (2019). Stress-associated neurobiological pathway linking socioeconomic 
disparities to cardiovascular disease. J. Am. Coll. Cardiol. 73, 3243-3255. doi: 10.1016/j.jacc.2019.04.042

Tefikow, S., Barth, J., Maichrowitz, S., Beelmann, A., Strauss, B., and Rosendahl, J. (2013). Efficacy of hypnosis in adults undergoing surgery or medical procedures: a meta-analysis of randomized controlled trials. Clin. Psychol. Rev. 33, 623-636. doi: 10.1016/j.cpr.2013.03.005

Timmers, I., Quaedflieg, C. W. E. M., Hsu, C., Heathcote, L. C., Rovnaghi, C. R., and Simons, L. E. (2019). The interaction between stress and chronic pain through the lens of threat learning. Neurosci. Biobehav. Rev. 107, 641-655. doi: 10.1016/j.neubiorev.2019.10.007

Tsigos, C., and Chrousos, G. P. (2002). Hypothalamic-pituitary-adrenal axis, neuroendocrine factors and stress. J. Psychosom. Res. 53, 865-871. doi: 10.1016/S0022-3999(02)00429-4

Ursin, H. (2014). Brain sensitization to external and internal stimuli. Psychoneuroendocrinology 42, 134-145. doi: 10.1016/j.psyneuen.2014.01.008

Ursin, H., Baade, E., and Levine, S. (1978). Psychobiology of stress: A study of coping men. New York: Academic Press.

Ursin, H., and Eriksen, H. R. (2004). The cognitive activation theory of stress. Psychoneuroendocrinology 29, 567-592. doi: 10.1016/S0306-4530(03)00091-X

Ursin, H., and Eriksen, H. R. (2010). Cognitive activation theory of stress (CATS). Neurosci. Biobehav. Rev. 34, 877-881. doi: 10.1016/j.neubiorev. 2009.03.001

Vachon-Presseau, E. (2018). Effects of stress on the corticolimbic system: implications for chronic pain. Prog. Neuro-Psychopharmacol. Biol. Psychiatry 87, 216-223. doi: 10.1016/j.pnpbp.2017.10.014

Vachon-Presseau, E., Martel, M.-O., Roy, M., Caron, E., Albouy, G., Marin, M. -F., et al. (2013). Acute stress contributes to individual differences in pain and pain-related brain activity in healthy and chronic pain patients. J. Neurosci. 33, 6826-6833. doi: 10.1523/JNEUROSCI.4584-12.2013

Verret, M., Lauzier, F., Zarychanski, R., Perron, C., Savard, X., Pinard, A. M., et al. (2020). Perioperative use of gabapentinoids for the management of postoperative acute pain: a systematic review and meta-analysis. Anesthesiology 133, 265-279. doi: 10.1097/ALN.0000000000003428

Videbech, P., and Ravnkilde, B. (2004). Hippocampal volume and depression: a meta-analysis of MRI studies. Am. J. Psychiatr. 161, 1957-1966. doi: 10.1176/ appi.ajp.161.11.1957
Wang, A. W.-T, Bouchard, L. C., Gudenkauf, L. M., Jutagir, D. R., Fisher, H. M., Jacobs, J. M., et al. (2018a). Differential psychological effects of cognitivebehavioral stress management among breast cancer patients with high and low initial cancer-specific distress. J. Psychosom. Res. 113, 52-57. doi: 10.1016/j. jpsychores.2018.07.011

Wang, L., Guyatt, G. H., Kennedy, S. A., Romerosa, B., Kwon, H. Y., Kaushal, A., et al. (2016). Predictors of persistent pain after breast cancer surgery: a systematic review and meta-analysis of observational studies. CMAJ 188, E352-E361. doi: 10.1503/cmaj.151276

Wang, K., Yee, C., Tam, S., Drost, L., Chan, S., Zaki, P., et al. (2018b). Prevalence of pain in patients with breast cancer post-treatment: a systematic review. Breast 42, 113-127. doi: 10.1016/j.breast.2018.08.105

Weinrib, A. Z., Azam, M. A., Birnie, K. A., Burns, L. C., Clarke, H., and Katz, J. (2017). The psychology of chronic post-surgical pain: new frontiers in risk factor identification, prevention and management. Br. J. Pain 11, 169-177. doi: 10.1177/2049463717720636

Wilder-Smith, O. H. G. (2011). Chronic pain and surgery: a review of new insights from sensory testing. J. Pain Palliat. Care Pharmacother. 25, 146-159. doi: $10.3109 / 15360288.2010 .505256$

Woolf, C. J. (2011). Central sensitization: implications for the diagnosis and treatment of pain. Pain 152 (Suppl. 3), 2-15. doi: 10.1016/j.pain.2010.09.030

Yakobov, E., Scott, W., Stanish, W., Dunbar, M., Richardson, G., and Sullivan, M. (2014). The role of perceived injustice in the prediction of pain and function after total knee arthroplasty. Pain 155, 2040-2046. doi: 10.1016/j. pain.2014.07.007

Conflict of Interest: The authors declare that the research was conducted in the absence of any commercial or financial relationships that could be construed as a potential conflict of interest.

Copyright $\odot 2021$ Munk, Reme and Jacobsen. This is an open-access article distributed under the terms of the Creative Commons Attribution License (CC BY). The use, distribution or reproduction in other forums is permitted, provided the original author(s) and the copyright owner(s) are credited and that the original publication in this journal is cited, in accordance with accepted academic practice. No use, distribution or reproduction is permitted which does not comply with these terms. 